\title{
The Impact of Community Sports Clubs on Place Attachment: From the Perspective of Club Commitment and Social Capital
}

\author{
Kozo Tomiyama \\ Department of Health and Sport Management, School of health and Sport Sciences \\ Osaka University of Health and Sport Sciences \\ 1-1 Asashirodai, Kumatori, Sennan, Osaka, 590-0496 Japan \\ E-mail: tomiyama@ouhs.ac.jp \\ [Received October 13, 2015; Accepted July 27, 2016; Published online August 29, 2016]
}

\begin{abstract}
There are rising expectations for community sporting clubs to serve a function that goes beyond simply playing a role as a place of activity, to contribute to revitalization of the local community. The purpose of this study is to reveal what kind of impact the commitment shown by sports club members towards their club has on place attachment. Structural equation modeling was used to analyze the relationship between the direct impacts that commitment to a community sports club has on place attachment and social capital as one benefit of joining a club, and the relationship between social capital and place attachment using a sample of members from two different community sports clubs. Results showed that while there was no significant correlation between commitment to a sports club and direct impact on place attachment, there was a significant correlation between commitment to a sports club and social capital and between social capital and place attachment. These results demonstrate that community sport club management that serves to enhance social capital is effective in enhancing emotional attachment to the local community and that a comprehensive community sports club that enables interaction between a diverse range of people is also beneficial in promoting place attachment.
\end{abstract}

Keywords: comprehensive sports club, place attachment, commitment, community sports

\section{Preface}

The Basic Act on Sport of Japan introduced in 2013 states in its preamble that "sport should play a role in reinvigorating the local community", clearly indicating the role that sport should assume in revitalizing local communities. The impact of sporting activities does not stop at the benefits gained by individuals participating in sport, such as the mental and physical benefits, but is also showing indications of spilling over to other factors, including economic benefits and urban development. However, it cannot be said that there has been sufficient validation of the social benefits that can be gained by individuals participating in sport and at present, such benefits are nothing more than the expectations of all those involved.

There has been an increased focus on the existence of comprehensive community sports clubs(CCSC) as a key player in paying forward the benefits of sporting activities to the local community. The establishment of such clubs was accelerated due to their incorporation in the Basic Plan for the Promotion of Sports formulated in 2000 and they were also positioned as a platform for the promotion of community sport in the Sport Basic Plan formulated in 2012. There is the expectation that CCSC will transcend their role as simply a place for sporting activities to fill the role of organizations that benefits social interests. It has been reported in a survey conducted by the Ministry of Education, Sports, Science and Technology of Japan that a large proportion of members of CCSC feel an emotional attachment to their local community, leading to speculation that club activities have some kind of impact on emotional attachment to the local community felt by club members. However, the mechanism behind the relationship between such clubs and place at- 
tachment is yet to be established. One possible aspect of this mechanism is a deepening of place attachment through commitment to club activities. Another possible aspect is a deepening of place attachment through an increase in social capital resulting from club activities.

The purpose of this study is to reveal what kind of impact the commitment shown by sports club members towards their club has on place attachment.

\section{Literature review}

\subsection{Commitment to community sports clubs and place attachment}

As a scale to gauge the commitment of members to club organizations, this study applied the organizational commitment scale. Research into the concept of commitment is ongoing in various fields, including sport sociology, sports psychology and sports management etc. as a scale to measure the level of commitment towards sporting organizations. Hashimoto et al. (2010) examined the commitment shown by university club members towards their club membership. This study has applied research into organizational commitment focusing on university club members conducted by Hashimoto to local community sports clubs.

While research from a variety of perspectives has been conducted on the relationship between people and the local community (Tomiyama, 2014), there has been a series of studies on "emotional attachment to a specific community" from the perspective of place attachment. In relation to the bond between individuals and a certain place, studies have been reveal that a special attachment to places that offer leisure activities (Kyle et al., 2003) and that professional sports fans develop an emotional attachment to their local community (Ninomiya, 2010). In recent years, there is an increasing call for research that demonstrates the role that sports clubs and teams play in creating emotional attachment to the community in which people reside, including studies into strategies implemented by professional sporting teams to promote place attachment and the expectations people have that CCSC will lead to further urban development.

Place attachment is defined as "the emotional bond between person and place" (Hidalgo and Hernandez, 2001). There are two elements to the emotional attachment felt by residents. These are "physical factors, including homes, land, various facilities and the natural environment etc." and "social factors, such as interpersonal relationships with the people that live there"' (Hikichi et al., 2009, Hidalgo and Hernandez, 2001). The emotional attachment born from sporting organizations can include the physical environment, such as the stadiums and arenas where professional sporting teams play and the gymnasiums and sporting grounds used by the residents. Moreover, the interpersonal relationships created between the participants in activities that are organized by community sports clubs can be considered to promote place attachment among sports consumers. Hikichi et al. (2009) has indicated that residents that rate their community environment are more likely to have a stronger emotional attachment to their local community, leading us to reason that a high level of involvement with sporting facilities and a high appraisal of such facilities can give rise to emotional attachment to the local community. Other research has indicated that the climate of an area and a higher level of interaction with natural and man-made features, and other people in the community, will give rise to increased place attachment (Suzuki and Fujii, 2008), leading us to speculate that stronger commitment to a sports club and an increased level of contact with community resources or facilities will further deepen emotional attachment to the local community.

\subsection{Commitment to a sports club and social capital}

It has long been reported that there has been a dilution of interpersonal relationships in local communities in Japan. There has been sporadic research in the field of sport and social sciences into the role of sport in order to resolve this social dilemma. Iida (2010) has made attempts to understand the connections made between people participating in community sports events from the prospective of social capital. Social capital is a concept theoreticized by Coleman (1988) and Putnam (1993) and is defined as "features of social organization, such as trust, norms and networks, that can improve the efficiency of society by facilitating coordinated actions" (Putnam, 2001).

In regard to the relationship between sports activities and social capital, Auld (2008), having established that sporting activities were effective in build- 
ing social capital, indicated that volunteer work and taking on a variety of roles, particularly in local sports clubs, helps to build social capital. It has also been indicated by Nagazumi et al. (2009) and Inaba et al. (2011) that the activities of community sports clubs help to increase social capital, leading us to speculate that the communication between those involved in sport works to increase social capital.

Further, the author speculate that the social capital shared by residents gives rise to an emotional attachment to the community in which they live. Due to the fact that daily interaction between residents has an effect on place attachment (Brown et al., 2003), the author can conceive that the interaction between residents gained through sports club activities is a factor contributing to place attachment. Further, research indicating that amicable relationships between neighbors (Sampson, 1997, Mesch and Manor, 1998) and that neighborhood events generated out of cohesion between residents can increase place attachment (Brown et al., 2003) and research indicating that the higher the level of interaction between people through community events the higher the level of place attachment (Suzuki and Fujii, 2008), the author can assume that amicable relationships between neighbors, a typical example of social capital, has a positive effect on emotional attachment to the local community.

\section{Formulation of hypothetical models}

Based on the existing research above, following three hypotheses was established.

Hypothesis 1: the commitment of local community sports club members towards their club increases place attachment.

Hypothesis 2: the commitment of local community sports club members towards their club increases social capital.

Hypothesis 3: social capital shared by members of local community sports clubs increases place attachment.

\section{Research method}

\subsection{Establishment of measurement scales}

In recent years, the three-dimensional model of organizational commitment proposed by Allen and
Meyer (1990) dominates research into the measure of organizational commitment. In this study, the author have adopted the club commitment scale comprised of 3 factors and 12 criteria developed by Hashimoto et al. (2010).

As a measurement scale to gauge place attachment of community sports club members, the author used a scale comprised of 3 factors and 13 scale items developed by Suzuki and Fujii (2008). This scale is comprised of 3 elements; place attachment (preference), place attachment (emotion) and place attachment (continued desire). The scale has been proven to be reliable by Suzuki and Fujii (2008).

In order to measure social capital for the purpose of this study, the author used a measurement scale comprised of 9 criteria designed to measure the social capital of CCSC members developed by Nagazumi et al. (2009).

\subsection{Preliminary study}

In order to test the reliability and validity of the measurement scales established for the purpose of this study, the author conducted a preliminary study with a sample of 70 university students enrolled at and living in the vicinity of Osaka University of Health and Sport Sciences.

The author conducted a confirmatory factor analysis of each of the measurement scales used and eliminated criteria with a factor loading of .50 or less and criteria that showed a strong correlation with the other criteria, ultimately establishing an organizational commitment scale comprised of 3 factors and 8 criteria. The $\alpha$ coefficient and AVE (Average variance extracted) were calculated at above the standard and so the author adopted these 8 criteria for the purpose of this study. Further, the place attachment measurement scale was reduced to 3 factors and 8 criteria. The $\alpha$ coefficient and AVE were calculated at above the standard and so the author adopted these 8 criteria for the purpose of this study. Finally, the social capital measurement scale was also reduced to 3 factors and 6 criteria. As with the other measurement scales, the $\alpha$ coefficient and AVE satisfied the standard values and so the author adopted these criteria for this study.

\subsection{Overview of this study and method of analysis}

Data for this study were collected by means of a 
questionnaire completed by members belonging to community sports club S located in Kagoshima and community sports club F located in Osaka. There are factors other than the sports club that may have an impact on the emotional attachment of club members to their local community. The author collected and analyzed data from sports clubs in two separate areas in order to minimize this impact. The manager at club $\mathrm{S}$ was asked to hand out the questionnaires and collected them via post and asked the manager at club $\mathrm{F}$ to both hand out and collect the questionnaires. The survey was conducted from November through December 2014. A total of 90 completed questionnaires were collected with a valid response rate of $100 \%$. The hypothetical models established for the purpose of this study were validated using structural equation modeling (SEM). Goodness of fit for the models was evaluated and indexed at $\chi^{2}(2.00 \leq$ standard value $\leq 3.00)$, CFI (Comparative fit index) (standard value $\geq .90$ ), TLI (Tucker-levis index) (standard value $\geq .90$ ), RMSEA (Root mean square error of approximation) (standard value $\leq .08$ ) and SRMR (Standardized RMR) (standard value $\leq .08$ ).

\section{Results}

\subsection{Basic attributes and type of activity of respon- dents}

Basic attributes and types of activity undertaken by the respondents are as shown in Table 1. About $43.3 \%$ of the respondents were male with $56.7 \%$ female, showing a slightly higher ratio of females. Regarding the age of the sample, the highest proportion of respondents was aged in their 40 s at $26.7 \%$. The majority of respondents had lived in the area for between 6-15 years at $33.3 \%$. Regarding the occupation, the majority of the respondents were corporate employees at $31.1 \%$, followed by stay-athome mums and dads (23.3\%) and unemployed $(12.2 \%)$. The majority of respondents had been a member of their respective sports club for between $1-5$ years at $47.7 \%$. The majority of respondents frequented their respective sports clubs between 4-6 times per month at $57.8 \%$. Among those, $48.9 \%$ answered 4 times a month accounting for $48.9 \%$ of all respondents, revealing that approximately half visited their sports club about once a week.
Table 1 Profiles of the respondents.

\begin{tabular}{|c|c|c|c|}
\hline & & $\mathrm{N}$ & $\%$ \\
\hline \multirow[t]{2}{*}{ Gender } & Male & 39 & 43.3 \\
\hline & Female & 51 & 56.7 \\
\hline \multirow[t]{6}{*}{ Age } & $20 \mathrm{~s}$ & 7 & 7.8 \\
\hline & $30 \mathrm{~s}$ & 15 & 16.7 \\
\hline & $40 \mathrm{~s}$ & 24 & 23.7 \\
\hline & $50 \mathrm{~s}$ & 19 & 21.1 \\
\hline & $60 \mathrm{~s}$ & 17 & 18.9 \\
\hline & 70 s and over & 8 & 8.8 \\
\hline \multirow[t]{5}{*}{ Years of residency } & $5 \mathrm{yrs}$ and under & 21 & 23.3 \\
\hline & $6-15$ yrs & 30 & 33.3 \\
\hline & $16-25 \mathrm{yrs}$ & 15 & 17.8 \\
\hline & $26-35 \mathrm{yrs}$ & 10 & 11.1 \\
\hline & 36 yrs or more & 13 & 15.5 \\
\hline \multirow[t]{7}{*}{ Occupation } & Corporate employee & 28 & 31.1 \\
\hline & House worker & 21 & 23.3 \\
\hline & Unemployed & 11 & 12.2 \\
\hline & Government employee & 9 & 10.0 \\
\hline & Manager/Self employed & 9 & 10.0 \\
\hline & Professionao & 3 & 3.3 \\
\hline & Other & 9 & 10.0 \\
\hline \multirow{4}{*}{ Length of membership } & Less than $1 \mathrm{yr}$ & 15 & 15.7 \\
\hline & $1-5$ yrs & 43 & 47.7 \\
\hline & $6-10 \mathrm{yrs}$ & 25 & 27.8 \\
\hline & 10 yrs or more & 7 & 7.8 \\
\hline \multirow[t]{4}{*}{ Frequency of visits } & $1-3$ times & 15 & 16.7 \\
\hline & 4-6 times & 52 & 57.8 \\
\hline & $7-9$ times & 12 & 13.3 \\
\hline & 10 times or more & 11 & 12.2 \\
\hline
\end{tabular}

\subsection{Verification of reliability and validity of meas- urement scales}

Next, confirmatory analysis of each of the three measurement scales was conducted; club commitment, place attachment and social capital to confirm reliability (standard value $\geq .70$ and AVE standard value $\geq .50$ ). The results, as shown in Tables 2 through 4, indicated that variables for all 3 scales satisfied the standard value. In terms of discriminate validity, only the AVE for the Norm factor for the commitment criteria fell below the square of the factor correlation, resulting in the validity falling slightly below the standard value. However, as the $\alpha$ coefficient was calculated at above the standard value and the author was able to confirm the discriminate validity for all other factors. The author continued to use for the purpose of the analysis.

\subsection{Verification of the hypothetical models}

Results of verification of the hypothetical models established for the purpose of this study are shown 
Table 2 Results of factor analysis of club commitment criteria.

\begin{tabular}{llrr}
\hline \multicolumn{1}{c}{ Factor } & \multicolumn{1}{c}{ Criteria } & Factor loading $\alpha$ coefficient & .747 \\
\hline Affective & & .617 \\
& This club holds considerable significance to me & .600 \\
\multirow{2}{*}{ Norm } & This club is like a family to me & .935 & .813 \\
& & .702 \\
& I believe I will feel a sense of guilt if I leave this club now & .593 \\
Self identification & I have achieved so much that I don't think I can leave this club now & .735 \\
& I believe that even if I wanted to, it would be difficult to leave this club now & .943 & .850 \\
& & I have a sense of loyalty to this club & .704 \\
& I have a strong sense of recognition that I am a part of this club & .763 \\
& I feel that the problems faced by this club are also my problems &
\end{tabular}

Factor correlation squares: Affective-Norm .007, Affective-Self identification .296, Norm-Self identification .004

Table 3 Results of factor analysis of place attachment criteria.

\begin{tabular}{|c|c|c|c|c|}
\hline Factor & Criteria & Factor loading & $\alpha$ coefficient & AVE \\
\hline \multirow[t]{4}{*}{ Preference } & & & .766 & .840 \\
\hline & I like the mood and feel of the community & .924 & & \\
\hline & I like this community & .940 & & \\
\hline & I can relax in this community & .884 & & \\
\hline \multirow[t]{4}{*}{ Emotion } & & & .802 & .692 \\
\hline & I feel an attachment to the community in which I live & .829 & & \\
\hline & I feel there is a place for me in the community in which I live & .851 & & \\
\hline & I feel a sense of belonging in the community in which I live & .816 & & \\
\hline \multirow[t]{3}{*}{ Continued desire } & & & .847 & .849 \\
\hline & There are things I don't ever want to change in the community & .879 & & \\
\hline & There are things I would be sad to lose in the community & .962 & & \\
\hline
\end{tabular}

Factor correlation squares: Preference-Emotion .145, Preference-Continued desire .493, Emotion-Continued desire .063

Table 4 Results of factor analysis of social capital criteria.

\begin{tabular}{|c|c|c|c|c|}
\hline Factor & Criteria & Factor loading & $\alpha$ coefficient & AVE \\
\hline \multirow[t]{3}{*}{ Trust } & & & .940 & .623 \\
\hline & I trust the residents in the community in which I currently live & .824 & & \\
\hline & I believe the majority of people living in the community are honest & .753 & & \\
\hline \multirow[t]{3}{*}{ Norm } & & & .870 & .671 \\
\hline & $\begin{array}{l}\text { I believe that in living in the community, it is important that families and } \\
\text { residents are friendly and come together to cooperate with one another }\end{array}$ & .848 & & \\
\hline & $\begin{array}{l}\text { Regardless of how personal the action, it is not preferable that people } \\
\text { ignore the rules and do as they please }\end{array}$ & .789 & & \\
\hline \multirow[t]{3}{*}{ Network } & & & .916 & .744 \\
\hline & $\begin{array}{l}\text { Residents in the community have established a connection where they will } \\
\text { assist one another when someone is in trouble }\end{array}$ & .796 & & \\
\hline & I value interpersonal relationships within the community & .924 & & \\
\hline
\end{tabular}

Factor correlation squares: Trust-Norm .336, Trust-Network .478, Norm-Network .383

in Figure 1. As for the goodness of fit indices, all of the indices came out at above the set indices, therefore the author was able to confirm goodness of fit of the models. Based on the number of samples, it is desired that $\chi^{2} / \mathrm{df}$ is equal to one or smaller, however; as there is no definite standard for $\chi^{2} / \mathrm{df}$ the author used the model as is for the purpose of this study. Of the 3 hypotheses established for this study, hypothesis 1: "the commitment of local community sports club members towards their club increases place attachment" scored a result of .061 as shown in Figure 1, revealing no significant correlation therefore hypothesis 1 was rejected.

Hypothesis 2: "the commitment of local commu- 


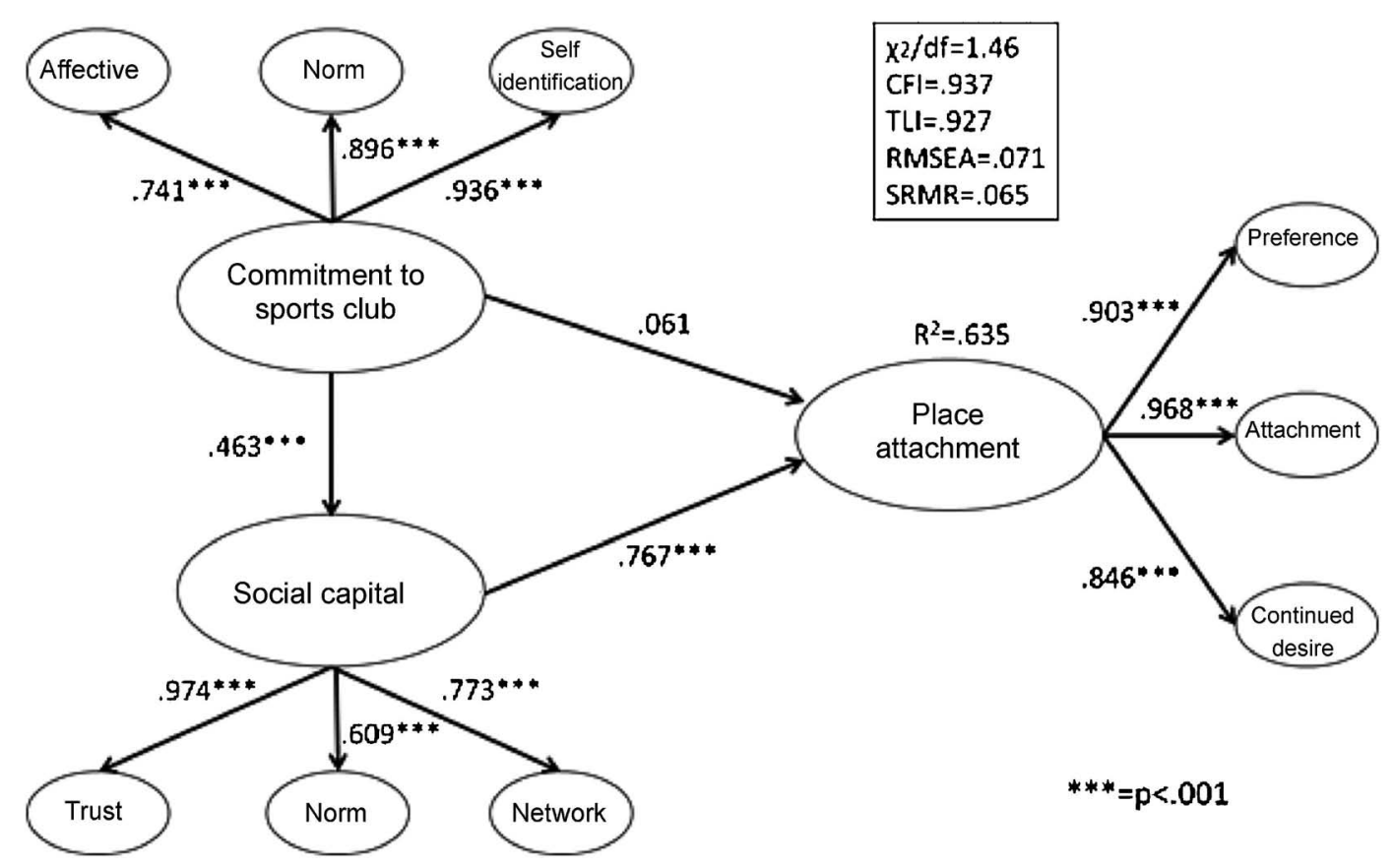

Figure 1 Verification of the proposed hypothetical model

nity sports club members towards their club increases social capital" scored a result of .463 , showing a statistically significant correlation of .1\% above the standard as shown in Figure 1, therefore this hypothesis was accepted.

Hypothesis 3: "social capital shared by members of local community sports clubs increases place attachment" scored a result of .767 , showing a statistically significant correlation of .1\% above the standard as shown in Figure 1, therefore this hypothesis was also accepted.

\section{Discussion}

Hypothesis 1 established for the purpose of this study was rejected. Tomiyama (2014) has shown that the attachment toward the sports organization is not directly linked to the place attachment using the case of professional sports. The results of this study shows the commitment of local community sports club members towards their club is not directly linked to place attachment. Factors that contribute to place attachment include both the physical and social environment (Hikichi, 2009). While the author did feel that by showing commitment towards a community sports club, interaction with the physical environment, such as sporting facilities and the natural environment suited to sporting activities etc., would increase, resulting in the attachment to such facilities and the attachment to the community in which such environments existed, the author was not able to confirm such a relationship in this study. The history of initiatives towards community development through sport in Japan is still relatively short and recognition of the benefits that can be gained through sports clubs is still superficial. In order to ensure that community sports clubs have an impact on place attachment, it is necessary to have members feel their potential benefits firsthand.

The author was able to however, confirm a significant correlation between commitment shown towards a sports club and social capital. This result supports the results shown in existing research (Nagazumi et al., 2006, Inaba et al. 2011). The author was also able to confirm a statistically significant correlation between social capital and place attachment, indicating that while there is no direct link between commitment shown towards a club and place attachment, place attachment can be enhanced through social capital. The author feel that strong commitments towards a community sports club will increase activities within the club, resulting in revitalizing interpersonal relationships and this in turn has the effect of enhancing place attachment. The results of this study showed that increased activity gives rise to a deepening of human interaction between the participants and that this in turn gives rise to place attachment. 


\section{Conclusion}

After consideration of the relationship between the commitment shown by club members towards a local community sports club and place attachment in this study, it was shown that the social capital born from the interaction of a large number of people, such as volunteers and the guardians of children active at community sports clubs (Auld, 2008) is effective in promoting place attachment. While the establishment of and development projects for CCSC that cater to a range of "activities", "age groups" and "orientations" is progressing in Japan, this study has indicated that the concept of "comprehensive" sports clubs with the potential to generate interaction between a larger number of residents and further build social capital will be effective in promoting emotional attachment among residents to their local community. However, social capital is just one of the benefits generated by community sports clubs and the author believes they have a large range of other ripple effects. There is a need for further research in the future to identify what kind of other benefits generated by sports clubs may have an effect on place attachment.

Lastly, the author collected and analyzed data from two separate sports clubs in order to eliminate the impact of local characteristics of specific areas. While this approach made it possible to achieve a more generalized result, it also made it difficult to understand individual factors that lead to the creation of social capital. In the future, it is necessary to use case studies to identify individual factors that will contribute towards the creation of social capital in each case.

\section{Acknowledgement}

I express my deepest appreciation to Mr.Toma Nagashima and Mr.Masaya Muneda, (Graduate School of Sport and Exercise Sciences, Osaka University of Health and Sport Sciences) for their assistance with data analysis of this study.

\section{References}

Auld, C. (2008). Voluntary sport clubs: The potential for the development of social capital. In M. Nicholson \& R. Hoye (eds.), Sport and social capital (pp.144-164). Oxford: Butterworth-Heinemann.

Allen, N. J. and Meyer, J. P. (1990). The measurement and antecedents of affective, continuance and normative commitment to the organization. J. Occup. Psychol., 63: 1-18.

Brown, B., Perkins, D. D., and Brown, G. (2003). Place attachment in a revitalizing neighborhood: Individual and block levels of analysis. J. Environ. Psychol., 23: 259-271.
Coleman, J, S. (1988). Social capital in the creation of human capital. Am. J. Sociol., 94: S95-S120.

Hashimoto, T., Karasawa, K., and Isozaki, M. (2010). A model of commitment to college student clubs: Form a semiorganizational perspective. Jpn. J. Exp. Soc. Psychol., 50: 76-88. (in Japanese)

Hidalgo, M. C. and Hernández, B. (2001). Place attachment: Conceptual and empirical questions. J. Environ. Psychol., 21: 273-281.

Hikichi, H., Aoki, T., and Ohbuchi, K. (2009). Attachment to residence: Affect of physical environment and social environment. Doboku Gakkai Ronbunshuu D, 65: 101-110. (in Japanese)

Iida, Y. (2010). Chiiki shakai ni okeru sports jissen to social capital no kanousei [The possibility of sports activity and social capital on local community]. J. Soc. Cap. Stud., 1: 91-108. (in Japanese)

Inaba, S., Yamaguchi, Y., and Ito, K. (2011). An Empirical study on the relations between the social capital of community sport clubs and public benefits. SSF J. Sport Everyone, 1: 72-81. (in Japanese)

Kyle, G., Graefe, A., Manning, R., and Bacon, J. (2003). An examination of the relationship between leisure activity involvement and place attachment among hikers along the Appalachian trail. J. Leisure Res., 35: 249-273.

Mesc, G. S. and Manor, O. (1998). Social ties, environmental perception, and local attachment. Environ. Behav., 30: 504-519.

Nagazumi, J., Enomoto, S., and Matsuda, Y. (2006). The mutually complementary relationship between the promotion of sports and social capital: Viewpoints and possibilities of social capital studies. J. Hum. Sci., Fac. Integr. Arts Sci., Univ. Tokushima, 14: 9-24. (in Japanese)

Nagazumi, J., Enomoto, S., and Sone, M. (2009). Chiiki sportsclub ga community ni motarasueikyou: Program henosanka to socialcapital tonokankeino kentou [The influences which the community-based sports club brings to community: The examination of the relationship between participation in the programs and the social capital]. Jpn. J. Lifelong Sport, 6: 1-11. (in Japanese)

Ninomiya, H. (2010). Place attachment of fans and sports spectator behavior in professional sports. J. Jpn. Soc. Sports Ind., 20: 97-107. (in Japanese)

Putnam, R. D. (2001). Bowling alone: The collapse and revival of American community. New York: Simon and Schuster.

Putnam, R. D. (1993). Making democracy work: Civic traditions in modern Italy. New Jersey: Princeton University Press.

Sampson, R. J., Raudenbush, S. W., and Earls, F. (1997). Neighborhoods and violent crime: A multilevel study of collective efficacy. Science, 277: 918-924.

Suzuki, H. and Fujii, S. (2008). Study on effects of place attachment on cooperative behavior local area. Infrastructure Plann. Rev., 25: 357-362. (in Japanese)

Tomiyama, K. (2014). The effects of team reputation and sense of community on building team identity: The case of J2League soccer club supporters. J. Jpn. Soc. Sports Ind., 24: 195-210. (in Japanese) 
Name:

Kozo Tomiyama

\section{Affiliation:}

Department of Health and Sport Management, School of health and Sport Sciences, Osaka University of Health and Sport Sciences

\section{Address:}

1-1 Asashirodai, Kumatori, Sennan, Osaka, 590-0496, Japan

Brief Biographical History:

1994-1996 Full time lecturer, University of Kitakyushu

1997-2004 Associate Professor, University of Kitakyushu

2000-2001 Visiting Professor, Old Dominion University, Virginia, U.S.A.

2005-2007 Associate Professor, Osaka University of Health and Sport Sciences

2008-current Professor, Osaka University of Health and Sport

Sciences

2010-2011 Visiting Professor, University of Illinois, Illinoi, U.S.A.

\section{Main Works:}

-Tomiyama, K., and Stewart, W. (2014) Psychological Attachment to Local Community and Team Loyalty. Asian Sport Management Review, 7: 35-60

-Tomiyama, K. (2014) The Effect of Team Reputation and Sense of Community on Building Team Identity. -In case of J2-League Soccer Club Supporters- Journal of Japan Society of Sports Industry, 24: 195-210

-Tomiyama, K. (2015) Commitment to Community Sport Clubs and Place Attachment. The $11^{\text {th }}$ Association of Sports Management Conference 2015 Proceeding. (Best Presentation Award) Membership in Learned Societies:

- Japanese Association for Sport Management.

- Japanese Association for Lifelong Sport.

-Japan Society of physical Education, Health and Sport Sciences.

- Japanese Society of Sports Industry. 